\title{
Columbamine-Mediated PTEN/AKT Signal Pathway Regulates the Progression of Glioma
}

This article was published in the following Dove Press journal:

Cancer Management and Research

\section{Hai-Tao Niu \\ Yang Liu \\ Yan-Zhou Wang \\ Yong Tian \\ Ming Yang \\ Hong-Sheng Jiang}

Department of Neurosurgery, Cangzhou Central Hospital, Cangzhou, Hebei 061000, People's Republic of China
Correspondence: Hai-Tao Niu

Department of Neurosurgery, Cangzhou Central Hospital, No. 16, Xinhua West

Road, Cangzhou, Hebei 06I000, People's

Republic of China

Email niujyrlps02495@I63.com
Purpose: At present, comprehensive therapy has been Aely used in e treatment of glioma, but the curative effect is not good, and the sur al rato spatients $j$ low. Therefore, it is crucial to explore further the regulatory mech sm of the oc ren and development of glioma and find potential therapeutic targets. aimed investiga , the columbamine (a tetrahydroisoquinoline alkaloid derived fo th 1 ome of chinese herbal medicine Rhizoma Coptidis) on glioma progressi

Methods: MTT, clone formation ay, und healing osay, and transwell assay were performed to detect the cell viability, prolife ion, migration, and invasion ability. Flow cytometry, TUNEL, and We morot were usea identify the apoptosis level in glioma cells. PTEN inhibitor (SF1 0 ) and AKT pctivator (SC79) were used to explore the mechanism of columbamine on gl na cell progi sion.

Results: Columbamine inh prolifer on, migration, invasion, and induces apoptosis in glioma cell lines 14 and 1 _ Columbamine prevents phosphorylation of AKT and promotes the exp ssion men. Blocking PTEN level or inducing phosphorylation of AKT attamuates ce pamine function on SHG44 cells proliferation, metastasis, and apor sis.

nclusio In this search, we find that columbamine could inhibit proliferation and me of gliom cell lines, and promote apoptosis of glioma cell lines via regulating PTEN $\$ T signal pathway. It provides a new theoretical basis for the development of antiglioma dru.

"ywords: columbamine, glioma, proliferation, PTEN, AKT

\section{Introduction}

Glioma is one type of tumor originating from central nerve cells. ${ }^{1}$ It is characterized by high incidence, high mortality, substantial invasion, and poor prognosis. ${ }^{2,3}$ In recent years, the prevalence of glioma has been increasing year by year. ${ }^{4}$ At present, the treatment of gliomas is mainly surgery, adjuvant chemotherapy, and radiotherapy. However, glioma often has infiltrative growth, so it is difficult to achieve the ideal effect of surgical treatment. ${ }^{5}$ The existence of a blood-brain barrier is difficult; it is difficult for drugs to penetrate the blood-brain barrier and play a role, resulting in the poor prognosis, high recurrence rate, and mortality of glioma. ${ }^{6}$ Therefore, more potential treatments need to be explored.

Recently studies showed that kinds of alkaloids acted as an anti-tumor role in glioma. Wang et.al found that nor-monoterpenoid indole alkaloids could inhibit the development of glioma stem cells. ${ }^{7}$ Two isoquinoline alkaloids from Scolopendra subspinipes mutilans promoted apoptosis and prevented the proliferation of glioma 
cells. ${ }^{8}$ Alkaloids abstracting from Lycoris Caldwell could induce glioma cell death by performing specific cytotoxicity. ${ }^{9}$ Chi $\mathrm{G}$ found that matrine could promote apoptosis and autophagy in glioma cells via controlling circRNA-104075/BCL-9 signal pathway. ${ }^{10}$

Columbamine is an alkaloid that was extracted from calumba. $^{11}$ In the previous research, it was found that Columbamine has anti-inflammatory and anti-tumor effects. Columbamine prevented the growth and deterioration of colon cancer by blocking the Wnt/ $\beta$-catenin signaling pathway. ${ }^{12}$ Columbamine also inhibits hepatocellular carcinoma development by preventing AKT and ERK1/2 signaling pathways. ${ }^{13}$ Meanwhile, Columbamine has a cytotoxic effect on osteosarcoma cells to inhibit tumor development. Traditional Chinese medicine therapy also occupies a particular position in the process of tumor treatment. Columbamine's effect on glioma has not been reported so far, so we were asked to explore its value. In this study, we investigated the function of Columbamine on glioma cell proliferation and metastasis.

\section{Methods and Materials}

\section{Ethics Statement}

The animal study was reviewed and approved Cangzhou Central Hospital. The research was carried ou based on the proposals in the Guidelines for $t^{1}$ and Use of Laboratory Animals of the Nation Instity s of Health.

\section{Cell Culture}

The human glioma cell line SHG44 and 251 cells were purchased from the Sci ce Cell Laborato . Cell lines were cultured in PR 1640 , Thermo-life, USA) with $10 \%$ FBS (Thermo Fisho $S \mathrm{~A}$ ) and $00 \mu \mathrm{L} / \mathrm{mL}$ penicillin and strepto ycin Beyot $C$ na) and placed at $37^{\circ}$ $\mathrm{C}$ with $5 \%$ 2. SH 44 and U.51 cells were added with columbamino $, 20,30,-0$, and $50 \mu \mathrm{M}$ ) for $24 \mathrm{~h}, 48 \mathrm{~h}$, and $72 \mathrm{~h}$.

\section{Western Blot}

Total protein was isolated from cells with RIPA lysis Mix (Beyotime, China). Briefly, $60 \mu \mathrm{g}$ protein extraction was loaded via SDS-PAGE and transferred onto nitrocellulose membranes (MILLIPORE, USA), then put them into a 5\% blocking solution for $3 \mathrm{~h}$. The membranes were incubated with primary antibodies at $4{ }^{\circ} \mathrm{C}$ for one night. After incubation with secondary antibodies, the membranes were scanned using an Odyssey, and data were analyzed with Odyssey software (LI-COR, USA). Anti-PCNA (102051-AP, 1:500), anti-E-cadherin (20874-1-AP, 1:1000), antiMMP2 (10373-2-AP, 1:500), anti-MMP7 (10374-2-AP) were purchased from Proteintech, anti-N-Cadherin (\#14215, 1:500) was purchased from CST. MMP9 (ab73734) was purchased from Abcam, and Gapdh (60004-1-Ig, 1:2000) was used as an internal control.

\section{Cell Viability Detection}

MTT assay was used to detect cell Cells were cultured in the 96-well plates fo $\times 10^{3} /$ weh Pvernight, cells were starved for $12 \mathrm{~h}$. After lumbamine reatment, the cells were added with $5,1 \mathrm{~g} / \mathrm{mL} \mathrm{N} \mathrm{T}(20 / 2 /$ well $)$ for 4 h. Removing supern ant and dding sO $(150 \mu \mathrm{L} /$ well), the plate was sh ing $.5 \mathrm{~h}$ at room temperature. The absorbance as read 490 using an Infinite 200PRO mi spectrop meter (BioTek, USA). The absorbance valu were normalized to the control.

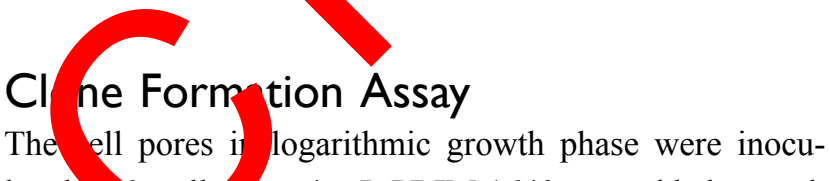
lated h well ate, 4 mL PRIM 1640 was added to each 1 and cultured in an incubator for 14 days; the culture dium was discarded, washed with PBS for 3 times, nxed with 4\% paraformaldehyde solution for $30 \mathrm{~min} ; 30$ in was stained with $0.1 \%$ crystal violet, washed, and dried at room temperature. Take pictures with the camera and observe the colony formation.

\section{Wound-Healing Assay}

The wound-healing assay was carried out on SHG44 and U251cell. A total of $5 \times 10^{5}$ cells were cultured in 6-well plates, and then the cells were gently scratched with a pipette tip. The fresh medium was changed. After columbamine treatment, the scratched spaces on the plate were evaluated by microscopy.

\section{Transwell Assay}

Cells in the logarithmic growth phase were adjusted to $2 \times 10^{5}$ cells/well of medium (without serum) and plated $1 \mu \mathrm{g} / \mu \mathrm{L}$ Matrigel into the upper chamber. The lower chamber was added with $500 \mu \mathrm{L}$ of the medium, and then incubate the plate at $37^{\circ} \mathrm{C}$ for $48 \mathrm{~h}$. Then, the invading cells were visualized by the crystal violet and inverted microscope. In the same way, the transwell migration experiment was carried out without the addition of the Matrigel matrix. 
A
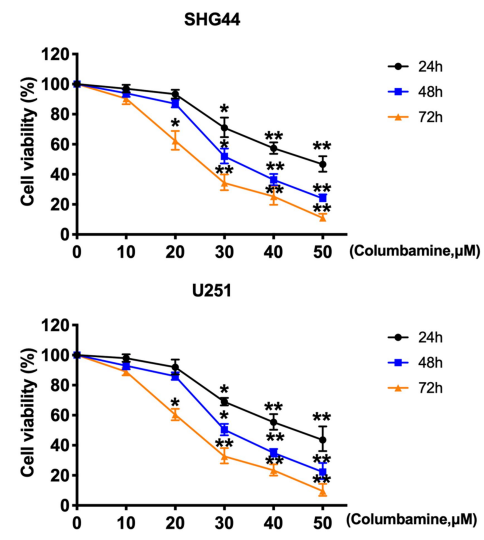

C
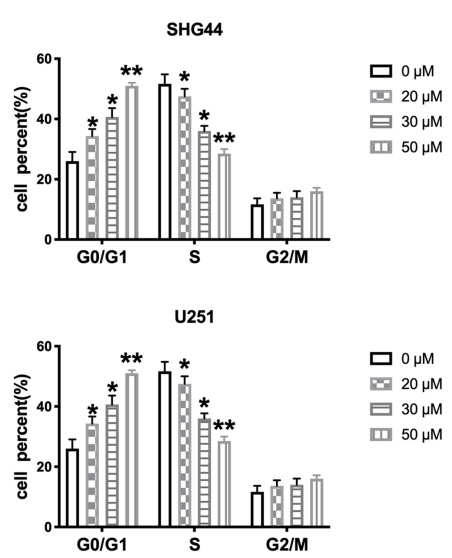

B

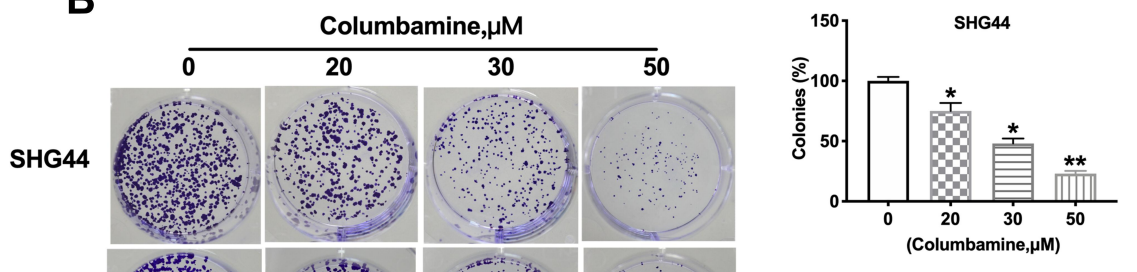

U251

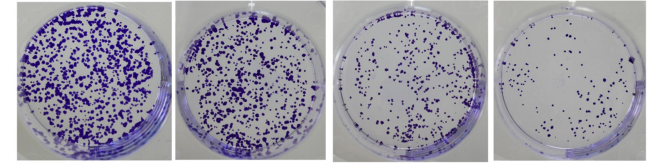

J251

D
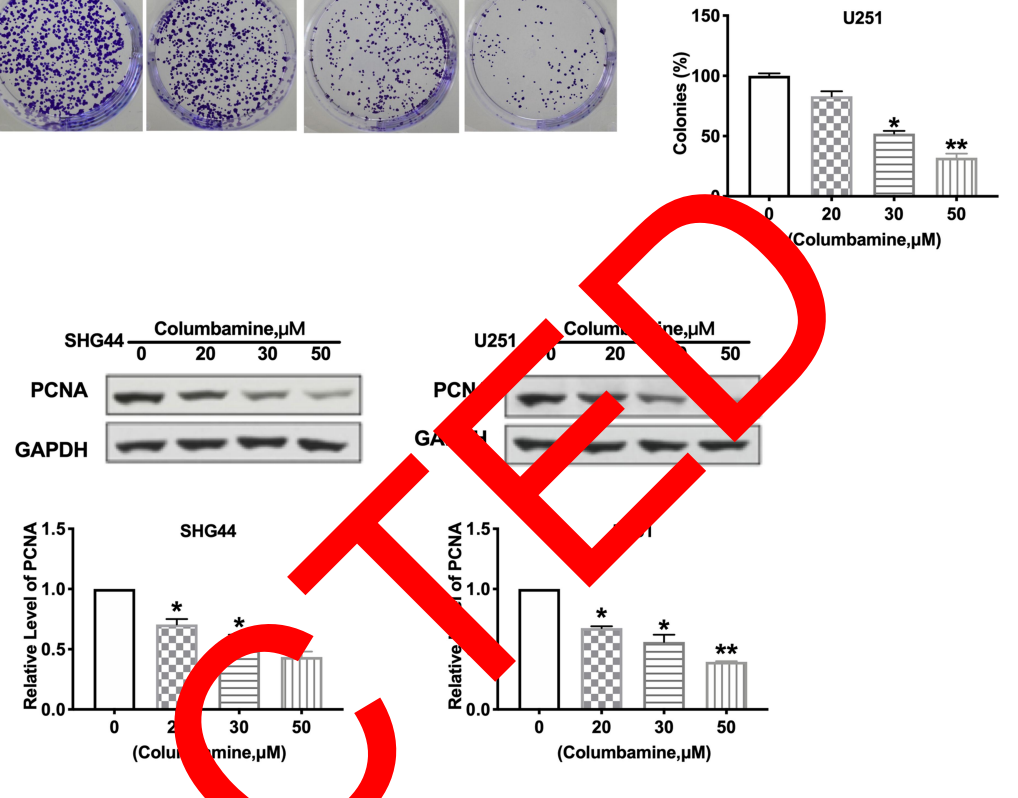

Figure I The function of columbamine proliferation on glioma cell lines. (A SG 44 . $48,72 \mathrm{~h}$. MTT assay was performed to measure cell viability. $n=10, * P<0.05$ vs M a , * ol vs $0 \mu \mathrm{M}$ group. (B) The colony formation assay of glioma cells was carried out after $0,20 \mu \mathrm{M}, 30 \mu \mathrm{M}$, and $50 \mu \mathrm{M}$ columbamine treatment $\quad * \mathrm{p}<0.05 \mathrm{vs}$ group, $* * P<0.0 \mathrm{I}$ vs $0 \mu \mathrm{M}$ group. (C) The cell cycle was detected by flow cytometry. $\mathrm{n}=5$, $* P<0.05$ vs $0 \mu \mathrm{M}$ group, $* * P<0.0$ I vs $0 \mu \mathrm{M}$ group. (D) The of $\mathrm{PC} A$ was de ted by Western blot. $n=7, * P<0.05$ vs $0 \mu \mathrm{M}$ group, $* * P<0.01$ vs $0 \mu \mathrm{M}$ group.

\section{Cell Apoptosis Assay}

The 9 cells were counted, aboy $\quad 10^{5}$ cells $/ \mathrm{m}$. Then, $1 \mathrm{~mL}$ cells were centrifuged, $100 \mathrm{rpm}, 0 \mathrm{~min}, 4^{\circ} \mathrm{C}$, and the medium was thrown ay. The cells vere washed with PBS and dropped $y$ aum. T $T^{\mathbf{y}}$ cells were resuspended and avoid light for $15, \eta, 2^{f} \mu \mathrm{L}$ Binding Buffer with10 $\mu \mathrm{L}$ Annexin V-F and IL PI. . N cytometry was used to measured poptos rate $\mathrm{w}, \mathrm{h}$.

\section{Cell Cy Assay}

Cells were co cted with $1 \mathrm{~mL}$ trypsin for 2 min, suspension the cell with $5 \mathrm{~mL}$ PBS, centrifuge at $1000 \mathrm{RPM}$ for 5 $\min$ at $4^{\circ} \mathrm{C}$. $10 \mathrm{~mL}$ PBS buffer was used to re-washed and discarding medium, Then the cells were fixed with $70 \%$ ethanol overnight. The next day, the cell medium was filtered with a 300-mesh sieve, centrifuged at 1000 RPM at $4^{\circ} \mathrm{C}$ for $5 \mathrm{~min}$, and the supernatant was discarded. The cells were avoided light and fixed with $1 \mathrm{~mL}$ PI solution and stated at $4^{\circ} \mathrm{C}$ for $30 \mathrm{~min}$. Flow cytometer was used to evaluate the cell cycle.

\section{TUNEL Staining}

TUNEL staining was performed with a One Step TUNEL Apoptosis Assay Kit (Beyotime, China) according to protocol. The TUNEL-positive cells containing apoptotic bodies were stained red. The apoptotic cells were statistics, and the rate of apoptosis cells among the total cells was statistical.

\section{Statistical Analysis}

All values are expressed as the mean \pm SEM. Statistical significances were measured by Student's $t$-test and ANOVA. A two-tailed value of $\mathrm{P}<0.05$ was indicated as a statistically significant difference. Data statistics were used the Prism 8.4. 


\section{Results}

\section{Columbamine Inhibits the Proliferation of} Glioma Cell Lines

To explore the function of Columbamine on glioma, we treated SHG44 and U251 cells with Columbamine (0, 10, $20,30,40$, and $50 \mu \mathrm{M})$ for $24,48,72 \mathrm{~h}$, and determining cell viability with the MTT assay. The cell viability of glioma cells was shown to concentration and time-dependent reduction following the treatment with Columbamine (Figure 1A). In the next experiment, we treated the glioma cells with $0,20,30$, and $50 \mu \mathrm{M}$ columbamine for $24 \mathrm{~h}$. The clone formation experiment showed the higher the concentration, the less the number of clones (Figure 1B). Next, we detected the cell cycle in SHG44 and U251 cells after columbamine treatment via flow cytometry. As Figure 1C shows, Columbamine blocks cell cycle progression from the G0/G1 to S phase. Proliferating cell nuclear antigen (PCNA) is a helper protein of DNA polymerase $\delta$, which may play a key role in cell cycle control. Then, we found the protein level of PCNA in SHG44 and U251 cells were concentration-dependent reduction after columbamine treatment for $24 \mathrm{~h}$ (Figure 1D). In summary,
Columbamine could inhibit the proliferation of glioma cells.

\section{Columbamine Prevents the Migration and Invasion of Glioma Cells}

Next, we discussed the effect of Columbamine on glioma cell migration and invasion. Wound healing assay showed that Columbamine significantly inhibited cell migration, and $50 \mu \mathrm{M}$ Columbamine almost completely inhibited cell migration (Figure 2A). In our experiments with glioma via transwell and Matrigel invasion a ay, we served that Columbamine could inhibit the ration and vasion of SHG44 and U251 cells in dosa. depend $t$ manner (Figure 2B). The migra and invasi glioma cells are accompanied by ch ges molecular proteins. Then, we detected the pressio if metas ons-related proteins, E-cadherin, N herin, MM MP7, and MMP9. We observed that Co nbamine induced expression of E-cad and inhibit the expression of N-cadherin, MN 2, MMP7, and MMP9 (Figure 2C). In summary, Col nbamine co $d$ inhibit the migration and invasion of gliom ells.

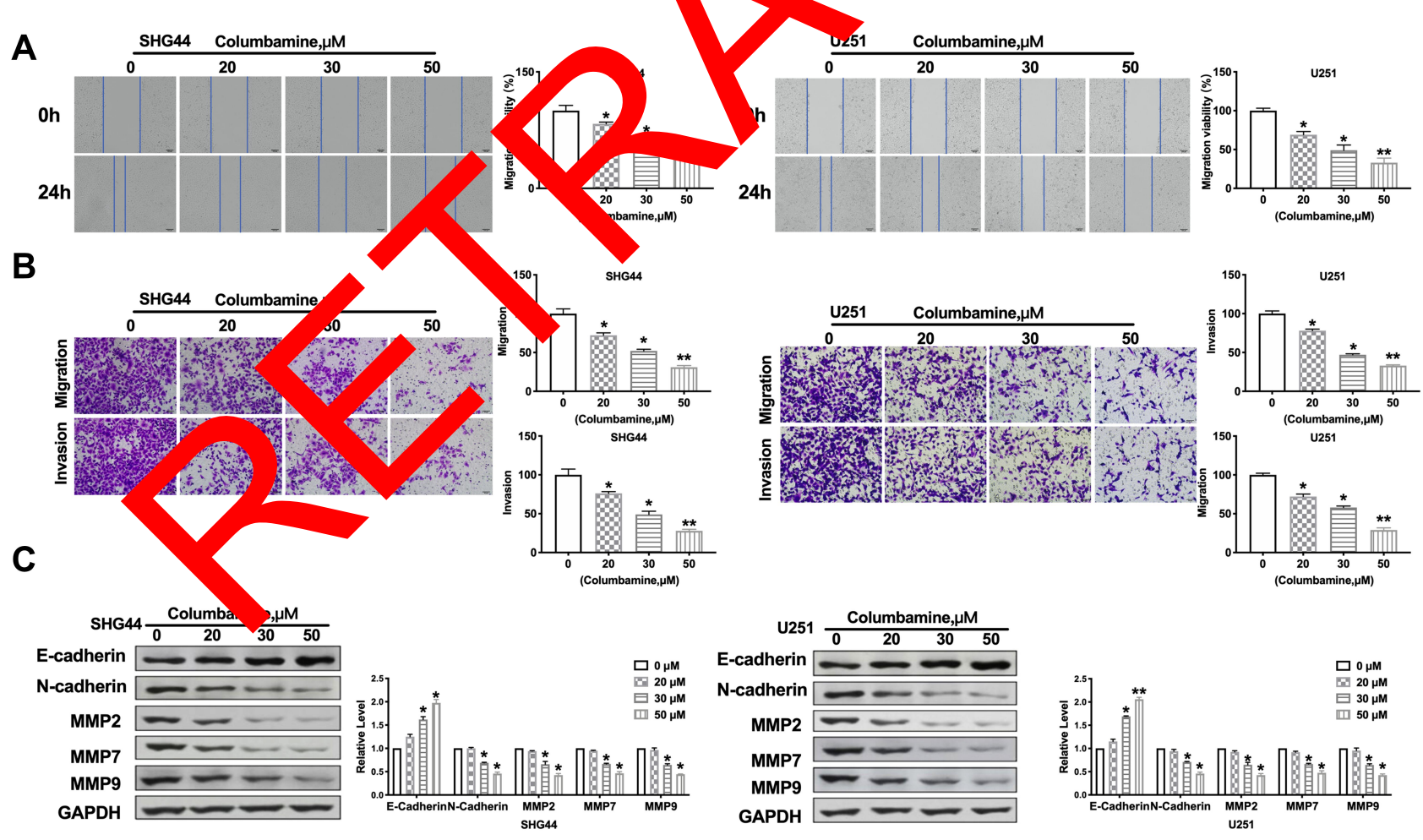

Figure 2 Columbamine regulates migration and invasion of glioma cells. (A) SHG44 and U25I cells were treated with Columbamine $(0,20 \mu \mathrm{M}, 30 \mu \mathrm{M}$, and $50 \mu \mathrm{M})$ for $24 \mathrm{~h}$. The migration of glioma cells was detected by performing wound healing. $n=5, * P<0.05$ vs $0 \mu M$ group, $* * P<0.01$ vs $0 \mu M$ group. (B) The migration and invasion ability of SHG44 and U25I cells. $n=5, * P<0.05$ vs $0 \mu$ M group, $* * P<0.01$ vs $0 \mu M$ group. (C) The proteins level of metastasis-associated E-Cadherin, N-Cadherin, MMP2, MMP7, and MMP9 in glioma cells after columbamine treatment. $n=6, * P<0.05$ vs $0 \mu M$ group, $* * P<0.01$ vs $0 \mu M$ group. 


\section{Apoptosis of Glioma Cells Induced by Columbamine}

Inducing tumor cell apoptosis is another way to limit tumor development. Further, we estimated the effect of Columbamine on glioma cell apoptosis. The apoptosis rates of SHG44 and U251 cells were detected by flow cytometry. The results showed that columbamine treatment significantly increased the apoptosis rate of glioma cells (Figure 3A). Additionally, TUNEL assay results showed that columbamine treatment could induce DNA damage and cell apoptosis (Figure 3B). Meanwhile, we appraised the expression of the apoptosis-associated protein. The level of Cleaved-caspase 3 and Cleaved-PARP were both upregulations after 30 and $50 \mu \mathrm{M}$ columbamine treatment, while, 30 and $50 \mu \mathrm{M}$ Columbamine could induce upregulated of $\mathrm{Bax}$ and downregulated of $\mathrm{Bcl} 2$ (Figure 3C). The above results indicated that Columbamine could trigger apoptosis of glioma cells.

\section{The Columbamine Regulation on Glioma Cells is Associated with PTEN/AKT Signal Pathways}

To further investigate the mechanism on Columbamine inhibited the development of glioma, we examined the potential pathways of glioma. PTEN/AKT signal pathway involved in series of tumor programs. Focusing on PTEN/ AKT signal pathways, we carried out Western blotting assay to explore the components of PTEN/AKT signaling pathways. The results performed that Columbamine inhibited the phosphorylation of AK and pro oted the expression of PTEN in SHG44 an U251 (Figu 4). Then, we speculated that Columb ine in ht regula the development of glioma celle a controlling $T^{\top}$ /AKT signaling pathways.

To verify is cons are, we ated SHG44 cells with PTEN inh (SF1670, "N, and AKT activator (SC79, $10 \mu \mathrm{M})$ or 24. After columbamine incubation, we

A
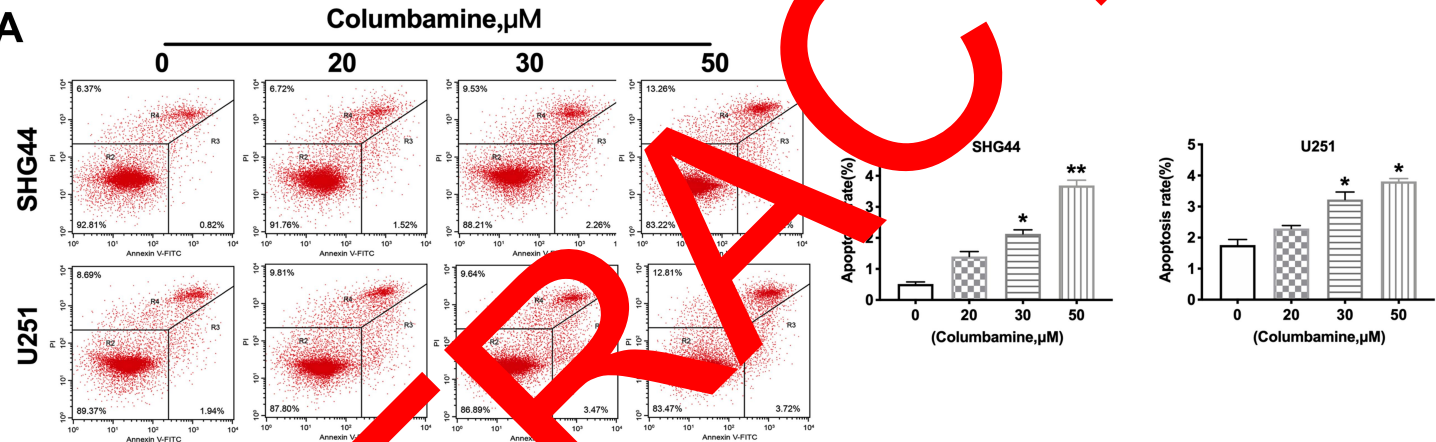

B
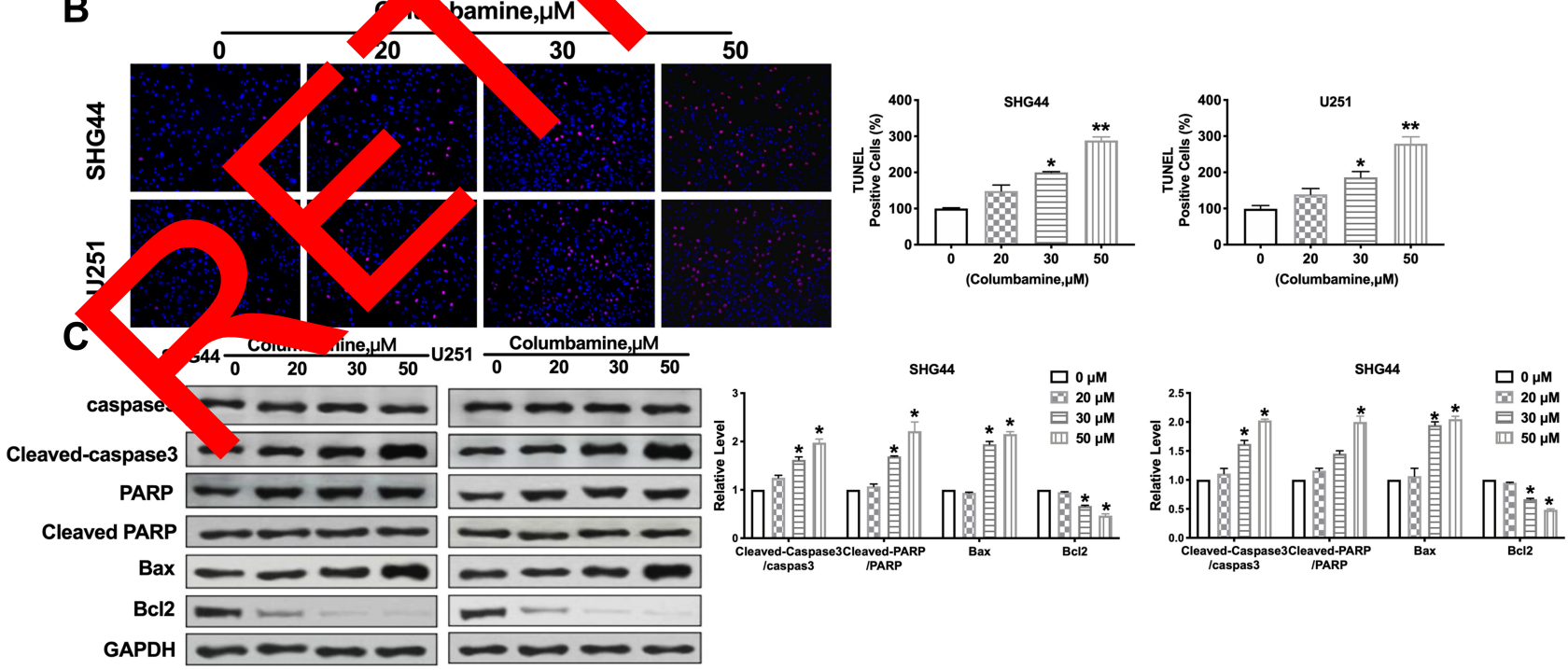

Figure 3 Apoptosis of glioma cells induced by Columbamine. (A) Flow cytometry was performed to quantify the apoptotic of glioma cells. $n=4$, $* P<0.05$ vs $0 \mu M$ group, $* * P<0.01$ vs $0 \mu \mathrm{M}$ group. (B) The TUNEL staining was performed on glioma cells after treatment with $0,20 \mu \mathrm{M}, 30 \mu \mathrm{M}$, and $50 \mu \mathrm{M}$ Columbamine for $24 \mathrm{~h}$. TUNEL-positive cells are shown. $n=7, * P<0.05$ vs $0 \mu \mathrm{M}$ group, $* * P<0.01$ vs $0 \mu \mathrm{M}$ group. (C) The expression of apoptosis-associated proteins (Caspase3, Cleaved caspase3, PAPR, Cleaved PAPR, Bcl2, and Bax) was detected in glioma cells after columbamine treatment. $n=6, * P<0.05$ vs $0 \mu \mathrm{M}$ group. 

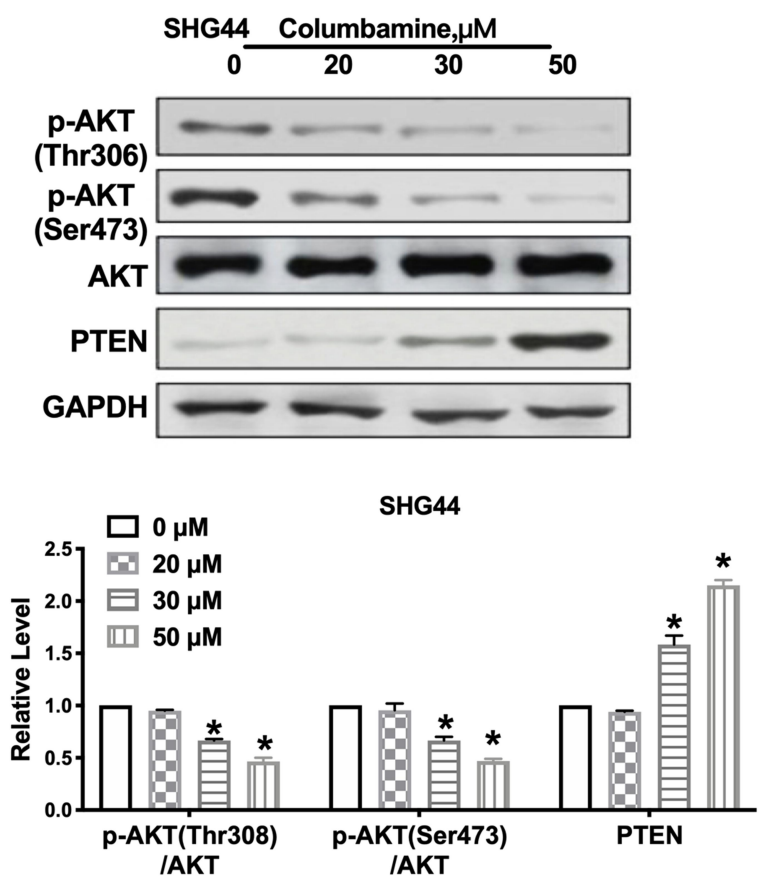
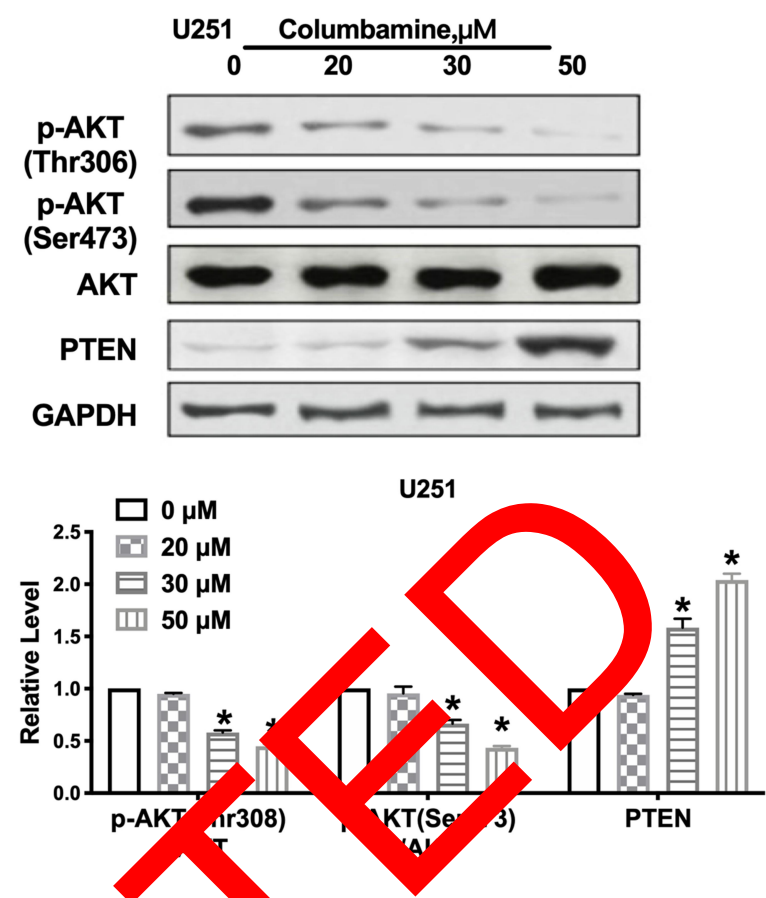

Figure 4 Columbamine inhibits the AKT signal pathway in glioma cells. Western blot was performed to measure the e, ssion of AKT, p-AKT (Ser473), p-AKT (Thr308), PTEN in glioma cells after cultured with Columbamine. $n=6, * P<0.05$ vs $0 \mu M$ group.

performed colony formation assay to detect the proliferather eutic effect f chemotherapy and biological regulators tion ability, as Figure 5A shows, SF1670 and SC79 has no ret bee confirmed. Therefore, we need to develop blocked the columbamine function on colony formatic effective and less toxic treatment methods to guide of SHG44 cells. Wound healing assay and Transwel migration assay revealed that $\mathrm{SF} 1670$ and $\mathrm{SC} 7 \mathrm{C}$ rered the migration ability of SHG44 cells (Fig $5 \mathrm{~B}$ a) $\mathrm{C}$ ). Transwell invasion assay verified that $\mathrm{SF}, \mathrm{\gamma}_{0}$ a could invert the role of Columbar ne in S 44 cells (Figure 5C). Furthermore, SF1 d SC79 a lished the function of Columbamine in the co apoptosis level (Figure 5D). Western $b^{\prime}$ showed that 1670 could recover the phosphor ation $\mathrm{cl}$ of AKT and PTEN, while SC79 could rest phosp orylation level of AKT, but not ress of $\mathrm{EN}$, which revealed that PTEN as ups eam of $\mathrm{KT}$ (Figure 5E). Taken together, Co nb? allicina ated glioma cell progression via PTEN/AKT vnal pathway (Figure 6).

\section{Discussion}

In the past years, the genetic basis of glioma has been elucidated in genomic research. In recent years, glioma has made significant progress in surgical and medical imaging technology, as well as radiotherapy, electric field treatment, chemotherapy, and immunotherapy. ${ }^{14-16}$ However, the inherent trend of the widespread of glioma cells in normal brain parenchyma severely limits the therapeutic effect, and the

\section{icar unplication.}

At present, for the treatment of tumors, not only the use of hemotherapy drugs, but traditional Chinese medicine is also constantly emerging. ${ }^{17-19}$ Because of the pharmacological effects of traditional Chinese medicine, such as inhibiting tumor cell proliferation, promoting cell differentiation and dissipation, preventing tumor metastasis to the whole body or nearby, reducing the side effects of chemotherapy, enhancing patients' self-immunity. ${ }^{20-22}$ In clinical, traditional Chinese medicine anti-tumor drugs have been widely used. $^{23,24}$ It is proved that allicin can activate the p53 gene and JNK pathway to play a role in G-M regulatory points of the cell cycle, and block tumor cells in the $\mathrm{M}$ phase. ${ }^{25}$ Oridonin, an effective component extracted from Rabdosia rubescens, can inhibit DNA synthesis and prolong cell cycle time by inhibiting the expression of cyclinB1, leading to G phase arrest of tumor cells. ${ }^{26}$ Wang et al confirmed that ethanol extract of hedyotis diffusa could effectively stimulate tumor cells to produce superoxide. Finally, the apoptotic signal network was activated to induce apoptosis of HL-60 cancer cells. $^{27}$

The previous report showed that Columbamine suppressed colon cancer cells via blocking Wnt/ $\beta$-catenin 

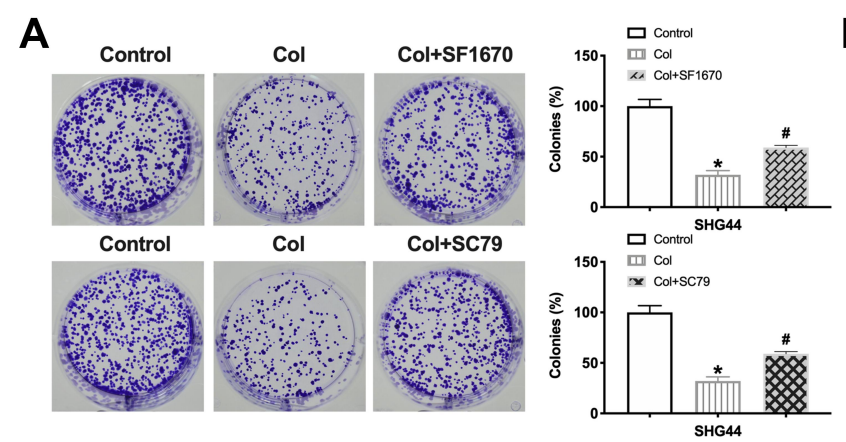

C

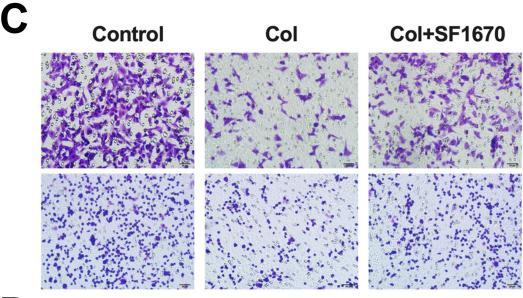

D
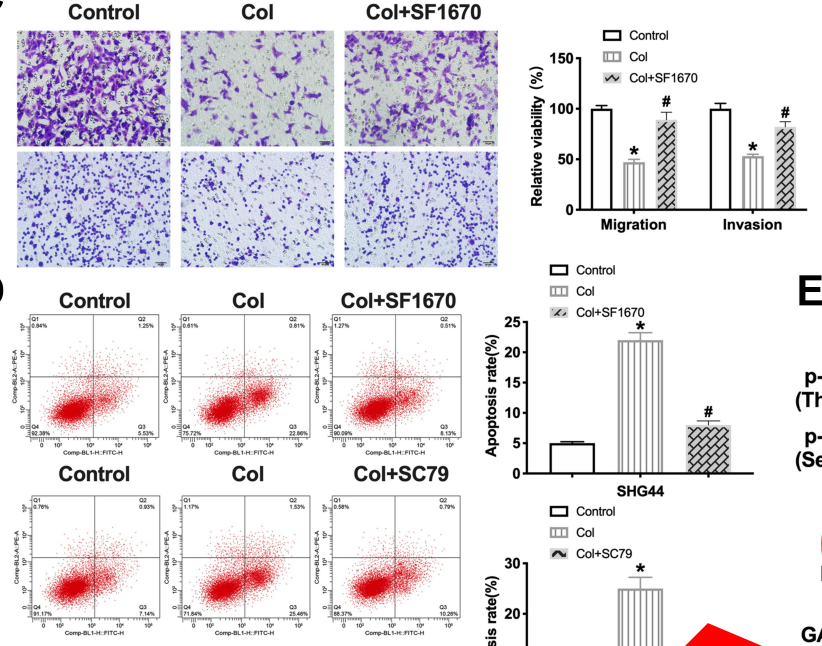

\section{口 $\mathrm{Control}$}

ㅁ Control

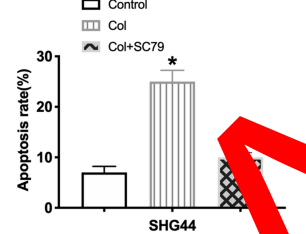

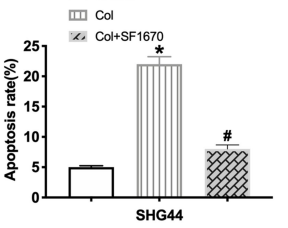
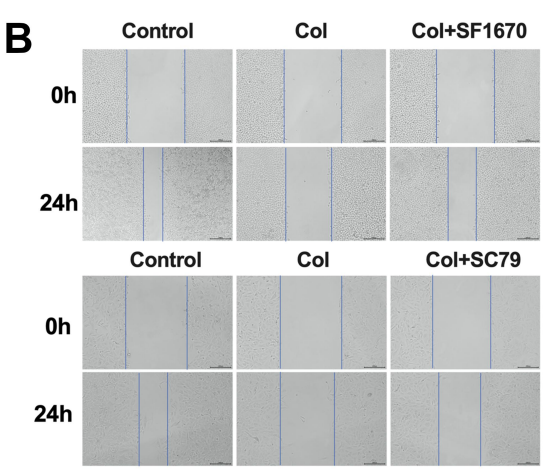
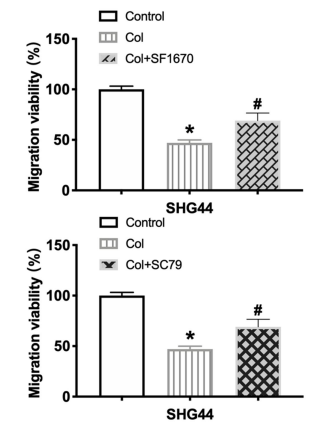

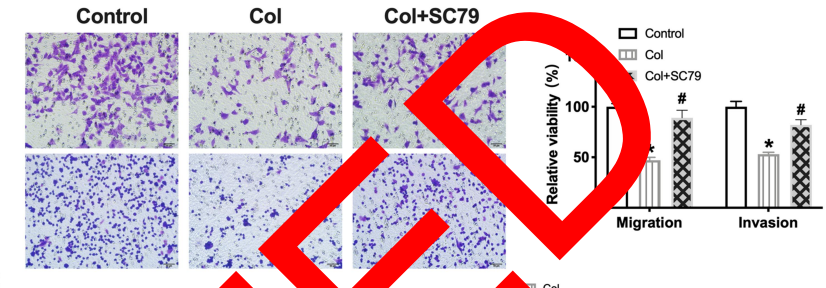

\section{E}

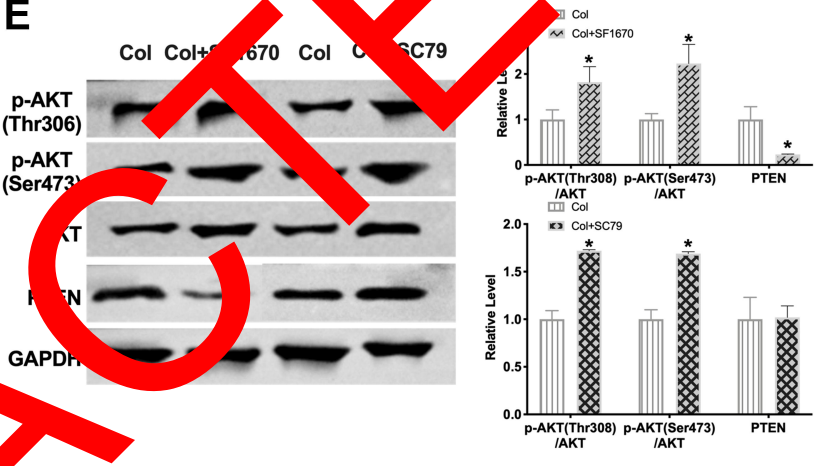

Figure 5 The columbamine inhibition of glioma cells is a ciated PTEN/ T signal pathways. (A) The colony formation assay of glioma cells was carried out after SFI670, SC79, and columbamine (Col) treatment. $n=4 \quad 0.05$ vs 0 group, ${ }^{\#} 05$ vs Col group. (B) The migration of glioma cells was detected by performing wound healing. $n=4,{ }^{*} P<0.05$ vs $0 \mu$ M group, ${ }^{\#} P<0.05$ vs Col gro $\quad$ (C) Th cytometry was performed to quantify the apop $c$ of gh expression of AKT, p-AKT (Ser473), p-AKT r 308), PTEN glioma cells after cultured with SFI670, SC79, and Columbamine. $n=5, * P<0.05$ vs $0 \mu M$ group.

signaling pathway. ${ }^{12} \mathrm{Li}>$ et al fous that Columbamine inhibited hepatocelly carcinoma cells ia abolishing of PI3K/AKT, p38 and, cRK1/2 MAPK signaling pathways. ${ }^{13}$ Columba preve $\mathrm{d}$ the development of metastatic osto arcon cos cells with low cytoto ity. ${ }^{28} \mathrm{~A}$ oresent, no research has shown any effect of Colun on on giroma. Here, we performed experiments to exp ve the function of Columbamine on glioma cell progression. We elucidated the inhibition effect of Columbamine on glioma cell proliferation, migration, invasion, and apoptosis level, which have specific guiding significance for the future clinical application. Meanwhile, NHA (normal human astrocytes) cells were treated with 50 $\mu \mathrm{M}$ Columbamine. The results performed that Columbamine did not affect the progression of NHA cells (Figure S1).

PTEN is a precise tumor suppressor gene. Its full name is $10 \mathrm{q}$ deleted tensin homologous gene, and its expression is deleted, mutated, or down-regulated in series of malignant tumors. ${ }^{29}$ PTEN could inhibit cell proliferation and hinder the development of the cell cycle, and the downstream PI3K/AKT pathway is an essential pathway for PTEN to inhibit cell proliferation. PTEN can inhibit the activation of PI3K and block the phosphorylation of AKT and its downstream protein kinases. On the one hand, it can cause cell cycle arrest in the G1 phase; on the other hand, it can also induce the expression of a variety of proapoptotic molecules and promote apoptosis. When the expression of PTEN decreases, the inhibition of PI3K/ AKT pathway weakens, and the phosphorylation of downstream protein kinases increases, thus promoting cell proliferation. $^{30,31}$ In our research, we found that Columbamine induced the expression of PTEN and prevented the phosphorylation of AKT, PTEN inhibitor, and AKT activator could abolish the function of Columbamine 
A

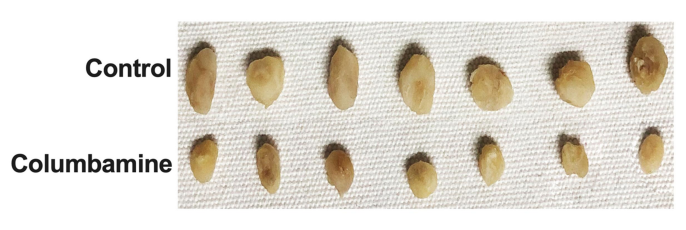

D

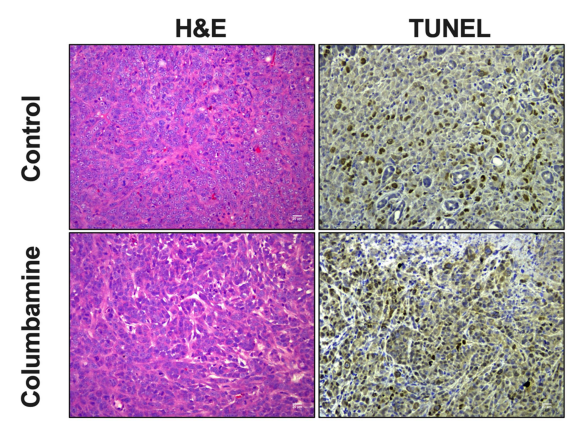

B

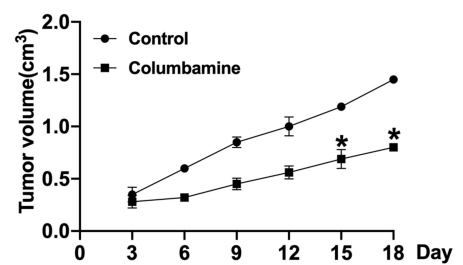

C

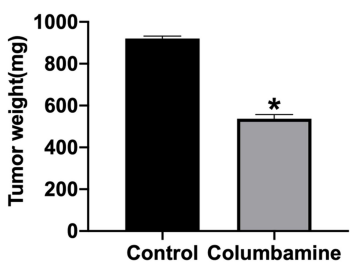

E

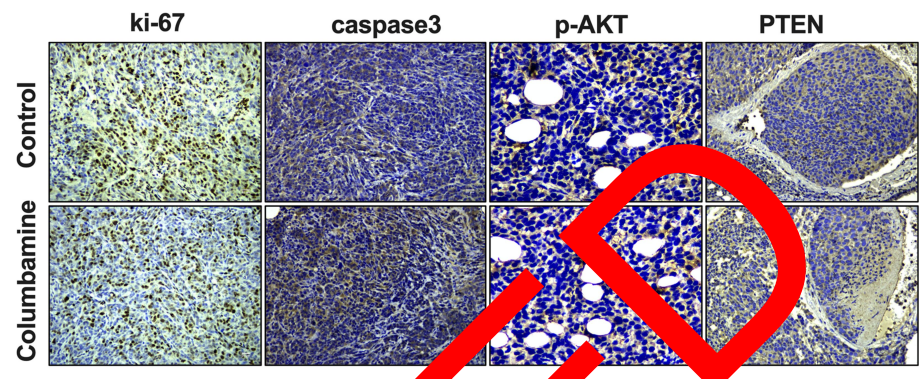

$\mathbf{F}$
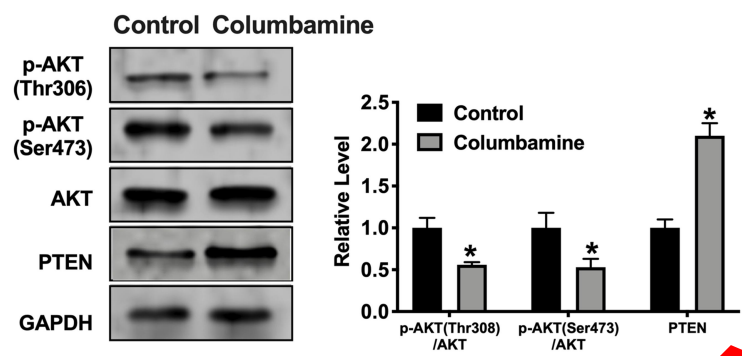

Figure 6 The Columbamine significantly reduces tumor growth in vivo. (A) thors mice 18 days after Columbamine and Control treated, respectively $n=7$. (B and $\mathbf{C}$ ) Tumor volume and weight were shown after the tum s wer olro $n=5, * P<0.05$ vs Control group. (D) $H \& E$ staining and TUNEL assay were performed. (E) Representative image of ki-67, caspase3, p-AKT tumor tissues. $n=5, * P<0.05$ vs Control group.

on glioma cell progression, which in cato underlying mechanism of Columbamir on glion In this study, we found that Columb ane n regulato AKT/ PTEN pathway to control th occurrence d development of glioma, indicating the expression AKT and PTEN may be related the delopment of glioma and may be used as an inde clinica cetection and diagnosis of glion

\section{Conclusic}

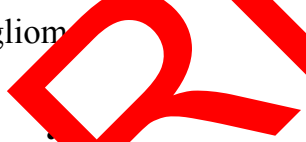

In this research, we investigated the function of columbamine on glioma progression. It was found that columbamine could inhibit proliferation and metastasis of glioma cell lines, and promote apoptosis of glioma cell lines via regulating PTEN/AKT signal pathway.

\section{Disclosure}

The authors report no conflicts of interest in this work.

\section{References}

1. Molinaro AM, Taylor JW, Wiencke JK, Wrensch MR. Genetic and molecular epidemiology of adult diffuse glioma. Nat Rev Neurol. 2019;15:405-417. doi:10.1038/s41582-019-0220-2

2. Jung E, Alfonso J, Osswald M, et al. Emerging intersections between neuroscience and glioma biology. Nat Neurosci. 2019;22:1951-1960. doi:10.1038/s41593-019-0540-y

3. Jones C, Baker J. Unique genetic and epigenetic mechanisms driving paediatric diffuse high-grade glioma. Nat Rev Cancer. 2014;14.

4. Cuddapah VA, Robel S, Watkins S, Sontheimer H. A neurocentric perspective on glioma invasion. Nat Rev Neurosci. 2014;15 (7):455-465. doi:10.1038/nrn3765

5. Glass Consortium. Glioma through the looking GLASS: molecular evolution of diffuse gliomas and the Glioma Longitudinal Analysis Consortium. Neuro Oncol. 2018;20(7):873-884. doi:10.1093/neuonc/noy020

6. Wen PY, Reardon DA. Neuro-oncology in 2015: progress in glioma diagnosis, classification and treatment. Nat Rev Neurol. 2016;12 (2):69-70. doi:10.1038/nrneurol.2015.242

7. Wang B, Dai Z, Yang XW, et al. Novel nor-monoterpenoid indole alkaloids inhibiting glioma stem cells from fruits of Alstonia scholaris. Phytomedicine. 2018;48:170-178. doi:10.1016/j.phymed.2018.04.057

8. Ding D, Guo YR, Wu RL, Qi WY, Xu HM. Two new isoquinoline alkaloids from Scolopendra subspinipes mutilans induce cell cycle arrest and apoptosis in human glioma cancer U87 cells. Fitoterapia. 2016;110:103-109. doi:10.1016/j.fitote.2016.03.004 
9. Cao P, Pan DS, Han S, et al. Alkaloids from Lycoris caldwellii and their particular cytotoxicities against the astrocytoma and glioma cell lines. Arch Pharm Res. 2013;36:927-932. doi:10.1007/s12272-0130089-3

10. Chi G, Xu D, Zhang B, Yang F. Matrine induces apoptosis and autophagy of glioma cell line $\mathrm{U} 251$ by regulation of circRNA-104075/BCL-9. Chem Biol Interact. 2019;308:198-205. doi:10.1016/j.cbi.2019.05.030

11. Wang Y, Han Y, Chai F, et al. The antihypercholesterolemic effect of Columbamine from Rhizoma Coptidis in HFHC-diet induced hamsters through HNF-4alpha/FTF-mediated CYP7A1 activation. Fitoterapia. 2016;115:111-121. doi:10.1016/j.fitote.2016.09.019

12. Lei C, Yao Y, Shen B, et al. Columbamine suppresses the proliferation and malignization of colon cancer cells via abolishing Wnt/ beta-catenin signaling pathway. Cancer Manag Res. 2019;11:8635-8645. doi:10.2147/CMAR.S209861

13. Lin Z, Li S, Guo P, et al. Columbamine suppresses hepatocellular carcinoma cells through down-regulation of PI3K/AKT, p38 and ERK1/2 MAPK signaling pathways. Life Sci. 2019;218:197-204. doi:10.1016/j.1fs.2018.12.038

14. Avila EK, Chamberlain M, Schiff D, et al. Seizure control as a new metric in assessing efficacy of tumor treatment in low-grade glioma trials. Neuro Oncol. 2017;19:12-21. doi:10.1093/neuonc/now190

15. Walsh KM, Wiencke JK, Lachance DH, et al. Telomere maintenance and the etiology of adult glioma. Neuro Oncol. 2015;17:1445-1452. doi:10.1093/neuonc/nov082

16. Jones C, Karajannis MA, Jones DTW, et al. Pediatric high-grade glioma: biologically and clinically in need of new thinking. Neuro Oncol. 2017;19(2):153-161. doi:10.1093/neuonc/now101

17. Xue T. Synergy in traditional Chinese medicine. Lancet Oncol. 2016;17:e39. doi:10.1016/S1470-2045(15)00557-4

18. Oncology The Lancet. Rethinking traditional Chinese medicines for cancer. Lancet Oncol. 2015;16(15):1439. doi:10.101 2045(15)00406-4

19. Xue T, Roy R. Studying traditional Chinese medicine. 2003;300:740-741. doi:10.1126/science.300.5620

20. Sun L, Mao JJ, Vertosick E, Seluzicki C, Yan Eval patients' expectations and barriers toward ditional cose mec cine utilization in China: a patient-sup sectional survey. Integr Cance Then 18;17:885-893. doi:10.1177/1534735418777117

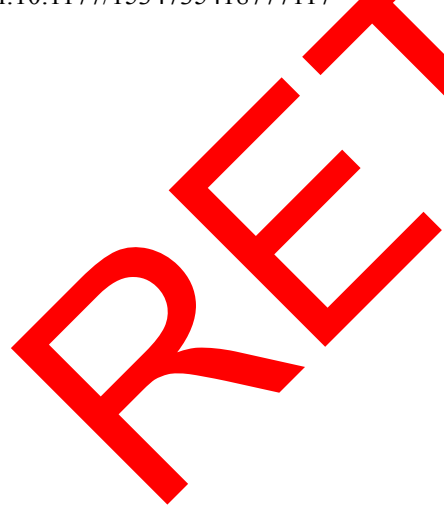

21. Parekh HS, Liu, G, Wei MQ. A new dawn for the use of traditional Chinese medicine in cancer therapy. Mol Cancer. 2009;8(1):21. doi:10.1186/1476-4598-8-21

22. Efferth T, Li PC, Konkimalla VS, Kaina B. From traditional Chinese medicine to rational cancer therapy. Trends Mol Med. 2007;13 (8):353-361. doi:10.1016/j.molmed.2007.07.001

23. Shi YL, Li MF. Biological effects of toosendanin, a triterpenoid extracted from Chinese traditional medicine. Prog Neurobiol. 2007;82:1-10. doi:10.1016/j.pneurobio.2007.02.002

24. Chan KK, Yao TJ, Jones B, et al. The use of Chinese herbal medicine to improve quality of life in women undergoing chemotherapy for ovarian cancer: a double-blind placebo-controlled randomized trial with immunological monitoring. Ann Oncol. 2011;22 (10):2241-2249. doi:10.1093/annonc/mdq749

25. Zeng T, Li Y, Zhang CL, et al. Garlic roppressed the hematological disorders induced by che nerapy d radiotherapy in tumor-bearing mice. J Food s 2013;78:H93 942. doi:10.1111/ $1750-3841.12137$

26. Shen QK, Deng H, Wan $\delta$ B, Trà VS, Quan Synthesis, and evaluation of in vitro a in vivo antica act $y$ of 14-substituted oridonin analogs: a vel and cent cell $c$ arrest and apoptosis inducer through o p53- M2 pathway. Eur J Med Chem. 2019;173:15 doi: o/j.ejmech 19.04 .005

27. Wang $\mathrm{C}, 7$ ou $\mathrm{X}$, Wang et al antitumor constituents from hedyoti Willd. Mole 2017;22.

28. Bao M,Cao Z, D, et al. Columbamine suppresses the proliferation and neovasculariz n of metastatic osteosarcoma U2OS cells with ytotoxicity. To ol Lett. 2012;215:174-180. doi:10.1016/j. toxlet.2012.10.015

9. Malaney P, versky VN, Davé V. PTEN proteoforms in biology and disease. Ce Mol Life Sci. 2017;74(15):2783-2794. doi:10.1007/ 00018-017 500-6

30. - Mazzio EA, Soliman KF. The effect of silibinin in enhancing toxicity of temozolomide and etoposide in p53 and NN-mutated resistant glioma cell lines. Anticancer Res. 2015;35 (3):1263-1269.

31. Xia M, Tong JH, Ji NN, et al. Tramadol regulates proliferation, migration, and invasion via PTEN/PI3K/AKT signaling in lung adenocarcinoma cells. Eur Rev Med Pharmacol Sci. 2016;20 (12):2573-2580.

\section{Publish your work in this journal}

Cancer Management and Research is an international, peer-reviewed open access journal focusing on cancer research and the optimal use of preventative and integrated treatment interventions to achieve improved outcomes, enhanced survival and quality of life for the cancer patient.
The manuscript management system is completely online and includes a very quick and fair peer-review system, which is all easy to use. Visit http://www.dovepress.com/testimonials.php to read real quotes from published authors. 